\title{
Irrational Wanting and Subrational Liking: How Rudimentary Motivational and Affective Processes Shape Preferences and Choices
}

\author{
Piotr Winkielman \\ University of California, San Diego \\ Kent Berridge \\ University of Michigan
}

\begin{abstract}
People's wanting and liking reactions reflect not only high-level beliefs, but also the operation of rudimentary biopsychological processes. Previous studies suggest that the following wanting and liking processes may be relevant to political behavior: irrational wanting (where wanting is triggered by activation of the brain dopamine system and becomes dissociated from liking); unconscious liking and wanting (where evaluative judgments and behavior are modified without awareness of the eliciting affective stimuli or of the underlying affective response); and fluency-based liking (where preferences are influenced by the ease of stimulus processing). This review suggests how conceptual and methodological tools from affective neuroscience and psychophysiology can refine our understanding of basic affective and motivational processes that shape political attitudes and choices.
\end{abstract}

KEY WORDS: affect, choice, emotion, preference, neuroscience

Citizens participate in the political process not only with their heads, but also their hearts. They are either enthusiastic about candidates or disgusted by them, engaged in or indifferent to elected officials' decisions, trusting or afraid of the government, passionate about social justice or hateful toward certain groups, hopeful or scared about the future, "mad as hell" or confident about the economy. Social scientists who appreciate these observations have long been interested in understanding the functions of emotion and motivation in political behavior (Abelson, Kinder, Peters, \& Fiske, 1982; Conover \& Feldman, 1986; Glaser \& 
Salovey, 1998; Holbrook, Krosnick, Visser, Gardner, \& Cacioppo, 2001; Kuklinski, Riggle, Ottati, Schwarz, \& Wyer, 1991; Marcus \& MacKuen, 1993).

In this paper we offer some insights into the role of the "heart" in political behavior from our research on core psychological and physiological mechanisms underlying emotion and motivation. We propose that core affective and motivational mechanisms produce phenomena that cannot be fully explained by traditional frameworks emphasizing rational considerations of attributes, values, expectations, and needs (de Sousa, 1987; Elster, 1999). Two phenomena support our proposal. The first is "irrational wanting"-wanting that is independent from liking for the same stimuli. We illustrate this phenomenon with animal research in affective neuroscience. The second phenomenon is "subrational liking"-liking that is independent from conscious, rational beliefs about the same stimulus. We illustrate this phenomenon with research showing that preferences can be influenced by (i) subliminal affective stimuli and (ii) the ease of stimulus processing. Throughout the paper, we describe how theoretical and methodological tools of affective neuroscience benefited our research and could contribute to political psychology. We hope to show that a dialogue between psychology and affective neuroscience can challenge the existing theories of emotion and motivation in political behavior, lead to the discovery of new phenomena, and contribute toward a comprehensive multilevel account (Cacioppo \& Berntson, 1992).

\section{Rational and Irrational Choice}

Rational choice theories of motivation view desire (or wanting) for an outcome as rationally connected to the anticipated enjoyment of (or liking for) the outcome. The following example illustrates the logic of such theories. Suppose that a ballot has a proposal for voters' consideration. The local taxes can be invested either in parks or in theaters. Keeping other factors constant, voters should want and choose the option promoting the more enjoyable outcome. Voters who enjoy parks should choose the park option; voters who enjoy theater should choose the theater option. The expectancy-value theories built on this logic perfectly capture our intuitive sense of rational behavior (Higgins \& Kruglanski, 2000; Pittman, 1998; Weiner, 1985; Wilson, Lindsey, \& Schooler, 2000). According to these theories, individuals want and choose outcomes they like better than all other outcomes. If liking changes, then changes in wanting and choice follow. For example, if voters learn that local parks are not as enjoyable as they thought, they may be more inclined to choose the theater proposal instead.

Miswanting. The affective-motivational equation described by the expectancy-value theories is elegant, but it does not fully capture the reality of everyday choices. In fact, people often choose outcomes that they later turn out not to like. Daniel Gilbert and Timothy Wilson (2000) have coined the term "miswanting" to refer to selecting outcomes that later turn out not to have been worth choosing. People choose wrongly because they hold incorrect expectations about the outcome. Such expectations can be wrong for many reasons: naiveté for 
outcomes they never experienced, current transient states of desire or distress that bias prediction, distortions of memory that lead to wrong predictions about future experiences, etc. (Elster, 1999; Gilbert \& Wilson, 2000; Kahneman, 1999; Mellers, 2000). All of these factors can distort expectations of how much something will be liked. A person who wrongly expects to like an outcome will miswant it and choose inappropriately. Yet such choices are not irrational by our definition. Desire remains rational as long as people choose what they expect to like at the moment of choice. A truly irrational choice would require choosing what you simultaneously expect not to like.

Utility definitions of rational and irrational choice. A helpful conceptual framework suggested by Kahneman considers rational and irrational choice in terms of utility values (Kahneman, 1999; Kahneman, Wakker, \& Sarin, 1997). A choice expresses the decision utility, or the degree to which one seeks the outcome in real behavior. Decision utility can be compared to other forms of utility that influence choice. Hedonic utility reflects actual liking for an outcome when the outcome is finally achieved. Predicted utility reflects expected liking for the outcome. Distortions of predicted utility account for the miswanted-but-rational choices mentioned above. Predicted utility is to a large degree determined by individuals' naïve theories of how well they will like the outcome in the future, often based on memories of how well they liked a similar outcome in the past (remembered utility).

In the utility value framework, an ideal choice maximizes all forms of utility. By contrast, when one makes a choice based on a wrong expectation, as in ordinary miswanting, the hedonic utility (actual enjoyment) of the chosen outcome is low. Yet such a choice remains rational. After all, at the moment of choice, the person expects to like the outcome (predicted utility) because of either an incorrect theory or an incorrect memory of having liked it before. Such miswanting can be called uninformed, naïve, not self-aware, perhaps even foolish-but not irrational.

Are there cases in which wanting is truly irrational? We suggest that truly irrational wanting represents a unique type of dissociation among utility forms. In particular, it results from a distortion of decision utility, as opposed to predicted utility. Irrational wanting occurs when an organism wants something that it does not like and does not expect to like. Is this possibility so bizarre that political scientists and psychologists could safely dismiss it? We suggest that there are several phenomena in the psychological laboratory and in real life that approach irrational wanting, and that irrational wanting could even exert control over real choices, at least under restricted circumstances.

\section{Core Motivational Processes and Irrational "Wanting”}

To understand the mechanisms of irrational wanting, it is useful to distinguish between two kinds of wanting. One is wanting in the ordinary sense-a cognitive and usually conscious desire for a reward. Ordinary wanting is rationally con- 
nected to predicted utility. That is, in ordinary wanting, people desire what they expect to like, and the more they expect to like it, the more they desire it. The other kind of "wanting," which we put in quotation marks to highlight the difference from ordinary wanting, can be dissociated from predicted utility and can lead to irrational choice. This "wanting" is created when cognitive representations of reward are assigned incentive salience (see below). In the brain, "wanting" appears to depend primarily on subcortical brain systems such as the mesolimbic reward system (Berridge, 2001; Berridge \& Robinson, 1998; Dickinson, Smith, \& Mirenowicz, 2000), whereas ordinary wanting appears to depend on cortical structures such as the prefrontal cortex and insular cortex (Balleine \& Dickinson, 1998; Bechara, Damasio, \& Damasio, 2000; Dickinson et al., 2000).

Incentive motivation. Because the concept of incentive salience is critical to the idea of irrational "wanting," it may be helpful to place the concept within the larger context of motivation theory. Early drive theories of motivation postulated that hedonic behavior (behavior toward stimuli with significant affective consequences) was controlled by need states (Hull, 1951; Mowrer, 1960). For example, people eat to reduce the unpleasant state of hunger. However, drive theories could not explain why, for example, people would eagerly consume tasty food when well-fed. Such problems led to the development of incentive theories of motivation, which posit that hedonic behavior is largely determined by the stimulus' incentive value, or its ability to function as a reward (Bindra, 1978; Toates, 1986). In incentive motivation theories, need states (e.g., hunger) are still important, but they are assumed to work indirectly by influencing the stimulus' incentive value. This influence is evident in the phenomenon of alliesthesia - a change in the hedonic value of an incentive as a function of a relevant motivational state (Cabanac, 1971). The reader is probably familiar with this phenomenon-as when food that tasted great after an exhausting hike in the mountains (e.g., macaroni and cheese) tastes bland at home after a regular day in the office.

Incentive salience. Researchers recently proposed that an incentive's hedonic value should be distinguished from incentive salience, or the ability of the reward stimulus to temporarily trigger intense pursuit regardless of its hedonic quality (e.g. Berridge, 2003; Berridge \& Robinson, 1998). Imagine a situation in which you are strongly "pulled" by some reward stimulus. This could be a sight of a cake in a bakery, or, more appropriate to a political domain, a monetary benefit offered by a candidate. This "pull" may change your behavior-you buy a cake or vote for the candidate. However, when the reward is actually consumed-the cake is eaten or the money received - the experienced pleasure may not be proportionate to the strength of the initial pull. That is, the activation of incentive salience can cause people to intensely "want" things that they do not even expect to like very much. In fact, "wanting" may be evolutionarily older than ordinary cognitive wanting. Such "wanting" might have evolved as an elementary form of goal-directedness to pursue particular innate incentives (food, drink, mates) even in advance of experience, later becoming harnessed to serve learned "likes." 
However, its continued independent existence in mammalian brains allows for the possibility of truly irrational pursuit, decoupled from liking, cognitive expectations, and other components of rational desire.

\section{Animals and Rational Choice}

To study irrational "wanting," it is helpful to have an animal model of rational versus irrational choice. Such a model can then be examined using techniques of affective neuroscience. Recent evidence from our studies on the animal model suggests that irrational choice is caused by overactivation of the brain's system of mesolimbic dopamine. Our animal model is based largely on the work of Anthony Dickinson, an experimental psychologist at the University of Cambridge (Dickinson \& Balleine, 2002). In studies using this model, we assess rats' expectations of the hedonic value of a food reward by measuring how much rats are willing to work for the reward when guided by cognitive expectations alone. Reward expectations are established by training the rats to work for sugar rewards, which are infrequent, so the rats learn to persist in working to earn them. Later the rats are tested for their willingness to work for these rewards under extinction conditions, when the rewards no longer come at all. Because there are no longer real rewards, the rats have only their expectations of reward to guide them. Without real rewards to sustain their efforts, the rats' performance in the extinction test gradually falls. But because the rats originally learned that perseverance pays off, they continue working, based largely on their ordinary wanting for reward. In this model, irrational "wanting" comes in when a reward cue is presented that the rats have never before encountered in a working situation, but that has been separately paired with reward (in classic Pavlovian fashion). There is no logical connection between the reward cue and working. Yet, just as a contextual cue to a drug can prompt a former addict to crave drugs anew, or a restaurant aroma can make a person suddenly desire food, the reward cue triggers a sudden burst of working by the rats. This cue-triggered burst of reward pursuit provides one of the two conditions needed for irrational "wants."

The other condition for truly irrational choice requires either a neurochemical manipulation or a real-life condition that creates a neurochemical brain change. Cue-triggered "wanting" can remain rational if its intensity is proportional to how much the reward would be "liked." But "wanting" becomes irrational if it strongly outstrips "liking." Truly irrational "wanting" has been produced in rats in an affective neuroscience experiment at the University of Michigan by the late Cindy Wyvell. She combined brain tweaks, in the form of microinjections that activated the brain's dopamine systems, with Dickinson's techniques for assessing ordinary cognitive wanting versus cue-triggered "wanting" (Wyvell \& Berridge, 2000). In one experiment, rats were first trained on some days to work for occasional sugar pellet rewards by pressing a lever. On different days, rats received Pavlovian pairings of a light or sound cue with a sugar pellet for which 
they did not have to work. Next, all rats received a microinjection of either amphetamine or drug-free vehicle solution into their nucleus accumbens (the brain target of mesolimbic dopamine systems that contribute to "wanting"). Finally, an extinction procedure, in which rats received no sugar rewards, tested their willingness to work. During this test, the reward cue (light or sound) was occasionally presented. The results clearly showed that the amphetamine microinjections did not change ordinary wanting based on cognitive expectation of liking (measured by baseline performance on the lever). However, amphetamine microinjection caused a sharp increase in cue-triggered "wanting" (400\% increase in performance on the lever).

A related experiment tested the effect of the same amphetamine microinjections on the liking of sugar by measuring rats' hedonic reactions as they received an infusion of sugar solution into their mouths. In rats, these liking reactions are homologous to the affective facial expressions that sweet taste elicits from human infants (Steiner, Glaser, Hawilo, \& Berridge, 2001). In this test of liking, amphetamine did not increase rats' positive affective reactions elicited by sugar, indicating that amphetamine did not increase the hedonic value (liking) of the sugar reward. In other words, the experienced hedonic utility of the sugar reward remained unchanged by mesolimbic activation, even though its decision utility was much greater (Wyvell \& Berridge, 2000).

What can we conclude about truly irrational "wanting"? This "wanting" has two sources that control its occurrence and duration: (i) a brain factor (mesolimbic dopamine activation), and (ii) a psychological factor (presence of reward cue). Irrational "wanting" is transient; it comes and goes with the reward cue. For the brain in a state of mesolimbic activation, the conditioned reward cue becomes a hyperincentive cue, able to trigger an irrational degree of pursuit. In such a state, the organisms "want" what they cognitively do not want, and what they proportionately do not like.

\section{Human Irrational Choice}

People also have brain dopamine systems, which may spontaneously activate in many situations. If a person's brain dopamine system were highly activated, and the person encountered a reward cue, the person might irrationally "want" the cued reward, just as the rat does, even if the person cognitively expected not to like it very much. To understand how these processes can work in everyday life, it is useful to consider an extreme case of dopamine-controlled irrational "wanting"-_drug addiction (Robinson \& Berridge, 1993, 2000).

Drug addiction. Addictive drugs activate brain dopamine systems when the drug is taken. In addition, if taken under certain conditions, addictive drugs leave dopamine systems neurally sensitized or hyperreactive for a long time (Robinson, Browman, Crombag, \& Badiani, 1998). The dopamine system is not constantly hyperreactive, but it reacts more strongly than normal if the drug is taken again- 
in a fashion that is psychologically gated by the associative context and cues that predict the drug. In some ways, a sensitized brain dopamine system is similar to a continuous microinjection of amphetamine into the brain: It becomes hyperresponsive to reward cues. Robinson and Berridge $(1993,2000)$ have suggested that this process may lead the addict to irrationally "want" to take drugs again-even if the addict does not really "like" drugs, or likes drugs less than the lifestyle he or she loses by pursuing the habit. This incentive-sensitization theory of addiction accounts for why addictive relapse is so often precipitated by encounters with drug cues, which trigger excessive "wanting" for drugs (Robinson \& Berridge, 1993, 2000). In an addict whose brain was sensitized, cues could trigger irrational "wanting" even long after withdrawal (because sensitization lasts longer), and regardless of expectations of "liking."

Irrationality in everyday life and politics? Do ordinary people show irrational cued "wanting" in less extreme situations? Right now this is a speculative question. But consider that addictive drugs merely involve functions that evolved to occur naturally: activation of the mesolimbic system and attribution of incentive salience to reward cues. That is, ordinary people's mesolimbic systems have the capacity to become strongly activated in certain situations, even in the natural range of experience. Consistent with these ideas, recent neuroimaging research with healthy, normal volunteers suggests that important social stimuli-such as money, gaze, attractive faces, and even social dilemma games - can activate relevant parts of the reward circuit (e.g., Aharon et al., 2001; Kampe, Frith, Dolan, \& Frith, 2001; Knutson, Adams, Fong, \& Hommer, 2001; Rilling et al., 2002). These data raise the possibility that mesolimbic irrational "wanting" could even apply to more abstract political goals and symbols.

Perhaps, then, it is possible that "politics is like a drug" in the sense of activating brain mesolimbic systems, at least under some circumstances. If so, one could ask the following questions: Are these systems involved when politicians ruin their careers in pursuit of rewards, such as money and sex, that they proportionately do not enjoy? Could the activation of the wanting system be responsi-

\footnotetext{
${ }^{1}$ Evidence that sensitization causes irrational cue-triggered "wanting" was recently found in another animal study similar to the one described earlier (Wyvell \& Berridge, 2001). Rats' brains were first sensitized by multiple amphetamine exposures. Next, rats were taken off the drug for 10 days. Even though the rats were drug-free at the time of testing, sensitization caused excessively high cuetriggered "wanting" for their sugar reward. For sensitized rats, irrational "wanting" for sugar came and went transiently with the cue, just as if they had received a brain microinjection of drug. Such evidence supports the idea that human drug addicts may fall into the grip of truly irrational "wanting." Their irrational "wanting" would be triggered by drug cues and would be targeted mostly toward drugs (because for addicts drugs were the primary reward paired with cues). However, it is also possible that some spillover of incentive salience could direct "wanting" to other types of rewards too, just as the rats" "wanting" was directed to sugar rewards. Indeed, evidence suggests that some cocaine addicts are hypersexual (Washton \& Stone-Washton, 1993) and that some addicts are even hyperresponsive to money rewards (Bechara, Dolan, \& Hindes, 2002). These observations raise the possibility that, depending on additional factors, irrational "wanting," once initiated, might be channeled to various other goals.
} 
ble for the electorate voting for certain "treats" (tax decreases, benefit packages) that bring little enjoyment when they are actually consumed? Could the activation of the wanting system cause voters to cling to candidates long after the reasons for their initial enthusiasm have disappeared? Of course, these possibilities are extremely speculative. It would be essential, although perhaps difficult, to investigate these ideas in a scientifically rigorous fashion. Better knowledge may help voters and politicians free themselves from irrational "wants" and lead them to make decisions that maximize all forms of utility.

Let us stress, however, that if irrational choice occurs at all in normal human life, it is probably rare. By the mechanism considered here, irrational choice would require not only high excitability in mesolimbic brain "wanting" systems, but also a simultaneous presence of incentive cues that engage brain mesolimbic systems. Whether these situations occur at all —and, if so, how frequently — are questions for the future. But the evidence discussed above suggests that, under the right conditions, irrational choice may be a powerful phenomenon. One may "want" more than one wants. Decision utility may transiently detach and soar above predicted utility as well as above eventual experienced utility. If so, outcomes will be pursued to a degree disproportionate to both their actual liking and their current expectation of being liked.

Implications for political theory. Could the psychological and neural mechanisms discussed above potentially inform political theory? As we described, the neuroscientific work on incentive salience led to a conceptual refinement of motivation theory in psychology. Looking at the brain allowed psychologists to see motivation in a way that behavioral and self-report data never suggested. Alteration of psychological models of motivation could have implications for political theory too, at least insofar as models of political behavior draw on psychological theories of motivation (e.g., Lavine, Borgida, \& Sullivan, 2000; Losier \& Koestner, 1999; Winter, 1993). Whether these models could be fruitfully extended by considering processes described by modern incentive motivation theories is a topic that political psychologists may wish to consider.

\section{Core Affective Processes and Subrational Liking}

In the preceding discussion of irrational "wanting," we set aside the question of what determines liking. However, liking may also sometimes violate the principles of rationality, and thus it may support choices that cannot be justified by people's beliefs. Our perspective here contrasts with traditional emotion research guided by appraisal and attribution theories. Those theories suggest that people's liking for an object reflects their beliefs about the properties of the object (Ellsworth \& Scherer, 2003; Weiner, 1985). For example, voters may like a certain proposal because they believe that it will increase general welfare.

Beliefs underlying such preferences are generally accessible to conscious awareness and can be changed by appeals to reason (Petty \& Cacioppo, 1986). 
For example, once voters learn that a proposal is flawed, they will evaluate it less favorably. However, as Blaise Pascal noticed centuries ago, "the heart has its reasons which reason knows nothing of." In social psychology, this view is associated with the statement that "preferences need no inferences," as in the title of the well-known article by Zajonc (1980). Our research concurs and shows that people's liking for stimuli may be influenced by rudimentary affective and perceptual mechanisms. These rudimentary mechanisms can generate "subrational" preferences that may be decoupled from higher cognitive processes underlying rational beliefs about the stimulus.

We explored the operation of such rudimentary mechanisms in two domains. One line of studies examined how liking is influenced by briefly presented emotional facial expressions. Another line of studies examined how liking reflects the ease with which information comes to mind. Here, we review some of this research and discuss its implications for political behavior.

\section{Preferences and Emotional Facial Expressions}

Facial expressions are potent social signals that are processed by biologically given affect programs (Ekman, 1984; Tomkins, 1962). Several studies suggest that facial expressions may influence people's liking for stimuli, even if the expressions are presented below awareness. For example, as shown originally by Zajonc and colleagues, subliminal expressions of anger, fear, disgust, or happiness can influence preference ratings for targets such as cartoon drawings, polygons, and ideographs (Murphy, Monahan, \& Zajonc, 1995; Murphy \& Zajonc, 1993; Niedenthal, 1990). This process appears to require minimal cognitive participation, as suggested by findings that under subliminal presentations the valence dimension influences judgments, whereas cognitive dimensions such as gender and size do not (Murphy \& Zajonc, 1993).

Influence on behavior. We recently showed that the influence of subliminal emotional facial expressions on affective responses goes beyond judgments and can change even a complex and consequential behavior (Winkielman, Berridge, \& Wilbarger, 2002). Specifically, under the cover story of a "gender detection task," we repeatedly exposed participants to subliminal happy, neutral, or angry facial expressions immediately followed by a supraliminal "masking" female or male face with a neutral expression. After the exposure phase, in one experiment we asked participants to pour a fruit-flavored beverage from a pitcher into a cup and drink it; in another experiment, we gave participants a single sip of the beverage and asked them to rate how much they liked the drink, how much they wanted to consume, and how much they would pay for a can of the beverage. The results depended on the participants' levels of thirst, as determined by a preexperimental measure. Thirsty participants who were exposed to subliminal happy facial expressions poured and consumed more of the drink than those who were exposed to angry facial expressions. Parallel effects of the subliminal stimuli were 
found on ratings of the single sip of the beverage. In answer to the questions "How much do you want this drink?" and "How much would you pay for this drink in a store?", thirsty participants exposed to happy expressions gave the drink higher ratings than those exposed to angry expressions and were willing to pay more than twice as much for it. None of these results were obtained for non-thirsty participants, which suggests that the impact of subliminal affective primes depends on the presence of a relevant need state, as predicted by the incentive motivation theory discussed earlier. In sum, this study suggests that behavior as well as preference ratings can be influenced by subliminal affective primes, and that such an influence is mediated by rudimentary affective and motivational processes.

Influence on conscious feelings. These findings raise an interesting question: Do rudimentary affective stimuli, such as subliminal facial expressions, trigger conscious affective feelings or only unconscious affect? By "unconscious affect" we mean a reaction caused by valenced stimuli that has valenced behavioral consequences, but which nonetheless is not subjectively felt, even upon introspection (Berridge \& Winkielman, 2003; Winkielman and Berridge, in press). We examined this issue as part of our beverage experiments. Specifically, immediately after the exposure to subliminal primes, we asked some participants to report on their hedonic state using standard mood questionnaires that ask about conscious feelings of pleasantness/unpleasantness, arousal, interest, hostility, fear, nervousness, irritability, enthusiasm, pride, etc. Perhaps surprisingly, the results showed that changes in behavior and ratings were not accompanied by changes in conscious mood. Thus, subliminal happy faces did not make participants feel better in general, nor did subliminal angry faces make them feel worse. Yet, after seeing happy rather than angry faces, participants poured and drank more of the beverage and also valued it more. This remarkable dissociation between the influence of affective stimuli on behavior and subjective feelings suggests that rudimentary affective processes can be truly "unconscious" (Kihlstrom, Mulvaney, Tobias, \& Tobis, 2000; Lane, Kaszniak, Ahern, \& Schwartz, 1997; Lang, 1993).

Rudimentary liking and rational persuasion. The effects observed in our priming studies demonstrate that rudimentary affective processes can shape preferences. Such preferences can be called "subrational," because they do not derive from higher, cognitive beliefs about the stimulus. As a result, they can produce "I like it, but I don't know why"-type phenomena. In this context, it is not surprising that preferences formed through rudimentary affective processes are fairly immune to various "rational" interventions, consistent with Spinoza's (1883) statement that "an affect cannot be restrained nor removed unless by an opposed and stronger affect."

Several studies support this idea. For example, one study first used subliminal facial expressions (happiness vs. anger) or descriptive information (favorable vs. unfavorable meaning) to induce an affect-based or cognition-based attitude toward a novel stimulus, a Chinese ideograph (Edwards, 1990, study 1). Later, the attitude toward the ideograph was challenged either with an opposite sublim- 
inal facial expression or with an opposite cognitive message. As expected, affectbased attitudes were resistant to cognitive information but were influenced by a stimulus with the opposite valence. In another study, an affect-based or cognitivebased attitude toward a novel drink was first induced by giving participants a sip of a tasty beverage or favorable information about its nutritional properties (Edwards, 1990, study 2). Later, participants were exposed to a counterattitudinal affective message (the drink's mildly aversive scent) or cognitive message (negative information about the drink). Again, the affect-based attitude was resistant to the cognitive message but was susceptible to the affective challenge (see Fabrigar \& Petty, 1999).

Another line of research explored whether people can resist the influence of rudimentary affect on their preference judgments (Wilson \& Brekke, 1994). In two studies, participants were asked to indicate their liking for Chinese ideographs preceded by subliminal happy or angry facial expressions (Winkielman, Zajonc, \& Schwarz, 1997). The participants liked the ideograms preceded by happy faces more than ideographs preceded by angry faces. Remarkably, this was true even when participants were fully informed about the presence and the biasing influence of subliminal primes (study 1) or when participants were given an alternative explanation for possible changes in their conscious mood by referring to background music (study 2). Why were these forewarnings ineffective? The reason, we suspect, was simple. Just as in the pouring and drinking study, the subliminal affective primes were operating on a level inaccessible to conscious awareness.

Contributions of neuroscience and physiology. In understanding these phenomena, neuroscience and physiology offer valuable insights. One critical question concerns whether emotional facial expressions elicit genuine "hot" affective responses or trigger only "cold" changes in stimulus evaluation. For example, some researchers posit that subliminal emotional expressions function in a semantic fashion, exactly like subliminal words (Clore \& Colcombe, 2003). According to this account, presentation of such stimuli activates general representations of positivity or negativity, which then guide judgments and behavior via regular interpretive mechanisms (Higgins, 1996). The "affect versus cognition" debates are difficult to resolve with traditional methods, such as self-reports and reaction times, but can be fruitfully addressed with physiology (see also Lazarus, 1999; Zajonc, 2000). In the case of reactions to facial expressions, such physiological data argue for an affective account. Specifically, neuroimaging studies suggest that emotional facial expressions are processed using neural shortcuts and activate basic subcortical circuitry, including the amygdala and its connections (Morris, Öhman, \& Dolan, 1999). Such activation occurs even when participants focus on other stimulus dimensions such as gender (Critchley et al., 2000), when facial expressions are presented subliminally (Morris, Öhman, \& Dolan, 1998; Whalen et al., 1998), or in patients impaired on higher visual processing (Morris, DeGelder, Weiskrantz, \& Dolan, 2001). Studies with subliminal and supraliminal 
emotional expressions also observed affective responses with measures such as facial electromyography (Dimberg, Thunberg, \& Elmehed, 2000; Rotteveel, de Groot, Geutskens, \& Phaf, 2001), skin conductance responses (Dimberg \& Öhman, 1996), and potentiated startle (Bradley, 2000). In sum, psychophysiological data suggest that processing of facial expressions involves "genuine" affect, and thus challenge cognitive models that try to explain their influence by means of purely semantic mechanisms.

Neuroscientific data have also led to a growing appreciation that affective processes have not only conscious but also unconscious forms. By definition, selfreports can only assess processes that are represented in experience, leading to the traditional focus of emotion research on conscious feelings. This focus is exemplified by a popular definition of affect as "hedonic experience, the experience of pleasure or pain" (Frijda, 1999, p. 194). In a similar vein, the popular "feelings-as-information" model proposes that affective influence occurs because people draw on conscious affective states to make many judgments and decisions (Schwarz \& Clore, 1996). However, a growing number of neuroscientific studies point out that the affective processes can be represented on multiple conscious and unconscious levels-a possibility consistent with the evolutionary perspective on emotion (Cosmides \& Tooby, 2000; Nesse, 1990). For example, one line of work suggests that somatosensory cortices may play a critical role in conscious affective experience but are less important for low-level influences of affect on perception, action, and learning (Damasio, 1999; Damasio et al., 2000). On the other hand, the work on the amygdala and related circuits suggests that they are crucial for the influence of affect on perception, action, and learning (Anderson \& Phelps, 2001), but are less important for conscious experience (Anderson \& Phelps, 2002). A similar conclusion is suggested by studies on animals, where lesions of cortical structures leave basic affective and motivational processes relatively unimpaired (Berridge, 1999; LeDoux, 1996; Steiner et al., 2001). These neuroscientific data, in conjunction with the behavioral studies described earlier (Winkielman et al., 1997, 2002), suggest that theoretical models of affective influence guiding research in psychology and political science may need to be expanded to include consideration of unconscious affect.

Rudimentary affect in everyday life and politics. Consider the potential implications of these findings for political behavior. In the age of "media politics," emotional facial expressions may play an important role in determining voters' attitudes. One line of studies documented a "smile-leniency" effect, in which persons with happy facial expressions were less likely to be judged guilty of possible wrongdoing - a phenomenon that may be particularly relevant during negative campaigning (LaFrance \& Hecht, 1995). Studies using videotaped excerpts of happiness/reassurance, anger/threat, and fear/evasion expressive displays by Ronald Reagan have shown that a 50 -second exposure to such expressions elicits emotional reactions in viewers, as reflected in electromyographic (EMG) responses and self-reports (McHugo, Lanzetta, Sullivan, Masters, \& 
Englis, 1985). There is even some evidence that emotional facial expressions may influence actual political behavior. One study reports that the host of the $\mathrm{ABC}$ evening news (Peter Jennings) exhibited significantly more smiling when referring to one 1984 presidential candidate, Ronald Reagan, than when referring to another candidate, Walter Mondale (Mullen et al., 1986). Newscasters of other networks (Dan Rather of CBS and Tom Brokaw of NBC) did not show such differential smiling. Voters who regularly watched $A B C$ news were more likely to vote for Reagan - the candidate Peter Jennings smiled upon. The authors of this study performed several correlational analyses to exclude obvious alternative explanations, such as the possibility that Reagan supporters were more likely to watch $\mathrm{ABC}$ news to begin with. However, as with all correlational studies, the causal interpretation is difficult, and confidence in this provocative finding requires further demonstrations.

Implications for subliminal stimuli in political advertisements. As an interesting intellectual exercise, consider how the findings on subliminal influence discussed earlier apply to a real instance of subliminal presentation in a political campaign. Such a presentation occurred during the $2000 \mathrm{Bush} /$ Gore presidential campaign in a television advertisement sponsored by the Republican National Committee. The advertisement promoted Bush's plan to reduce the impact of rising drug prices on seniors by adding a prescription drug benefit to Medicare. This plan was contrasted with Gore's preference for a national health plan under which medical decisions allegedly might be controlled by government bureaucrats. As the narrator intoned that argument, letters, word fragments, and whole words emerged from the top and bottom of the screen, moved toward the center, and then quickly became large enough to read. Subliminal presentation occurred just before the appearance of the word "BUREAUCRATS"; a word fragment of "BUREAUCRATS"- namely "RATS"- appeared on the screen in full size for about one-thirtieth of a second, immediately before the emergence of the longer word, which remained on the screen for several seconds (Berke, 2000). The advertisement was aired about 4,000 times in 33 markets before the occurrence of the subliminal "rats" became publicly known after a viewer videotaped and replayed the sequence in slow motion. The presence of the subliminal stimulus in this advertisement was quickly disavowed by the campaign as an inadvertent mistake due to the editing process, and the ad was removed from further broadcast. During the ensuing furor, much public doubt was expressed about whether such subliminal techniques could ever have any significant effect on voter attitudes or behavior (Berke, 2000).

Although we make no judgment as to the intentions of the advertisement's creators, we note that, despite the public doubts, the ad could have been effective in influencing voters' attitudes. If the results of our consumption study are a guide (Winkielman et al., 2002), the subliminal perception of "rats" might be expected to arouse an implicit negative reaction that changed the value of the following target, "bureaucrats" (presuming that "rats" is a negative emotional stimulus for 
many people). The viewer who consciously evaluates the potential role of bureaucrats in his or her medical future could be more negative toward nationalized health care after the subliminal presentation. It is worth emphasizing that subliminal effects on judgment and behavior obtained in experimental studies are typically fleeting and relatively weak (Dijksterhuis \& Bargh, 2001). However, an actual policy judgment made at that moment might conceivably be more enduringly tagged by subliminal manipulation. Of course, this theoretical possibility does not imply that the changes in preferences resulting from subliminal presentation of words like "rats" are practically significant, nor that subliminal presentation is more effective than traditional overt techniques of persuasion. Still, we would like to suggest that the possibility of subliminal influence should not be dismissed out of hand before being empirically examined (see also Greenwald, 1992; Strahan, Spencer, \& Zanna, 2003).

\section{Preferences and Ease of Information Processing}

Perhaps a more common source of subrational influences on liking was examined in our research on the affective consequences of manipulating the ease, or fluency, of information processing. Starting with classic aesthetics theory, researchers noted that people can like stimuli not only because of their content but also because they are "easy on the eyes" as a result of their good form, balance, symmetry, contrast, or proportions (Tatarkiewicz, 1970). A similar observation was made by Adam Smith in his "Lectures on Jurisprudence," in which he wrote that "easy connection . . renders objects agreeable" (Heilbroner \& Malone, 1986, p. 45). In experimental psychology, interest in the fluency-preference link was stimulated by research into the mere-exposure effect-the observation that repeated exposure to an initially neutral stimulus enhances liking for that stimulus (Bornstein, 1989; Zajonc, 1968). Several authors proposed that the mereexposure effect might be based on changes in fluency (Bornstein \& D'Agostino, 1994; Klinger \& Greenwald, 1994; Seamon, Brody, \& Kauff, 1983). This proposal is consistent with observations that repeated exposure facilitates stimulus processing, as reflected in faster reaction times and higher recognition accuracy (e.g., Haber \& Hershenson, 1965; Jacoby \& Dallas, 1981; Whittlesea, Jacoby, \& Girard, 1990; Witherspoon \& Allan, 1985) as well as reduction of activity in relevant brain areas (Desimone, Miller, Chelazzi, \& Lueschow, 1995; Rolls, Baylis, Hasselmo, \& Nalwa, 1989).

The idea of a fluency-liking link suggests that any variable that increases perceptual fluency should result in more positive evaluations of the stimulus, even with a single exposure. Several of our studies are consistent with this conjecture (Reber, Winkielman, \& Schwarz, 1998; Winkielman \& Cacioppo, 2001; Winkielman, Schwarz, Fazendeiro, \& Reber, 2003). The logic of these studies is rather straightforward. Participants are asked to indicate their liking for a variety of stimuli. While participants view the stimuli, fluency is unobtrusively 
manipulated through various methods. In some studies, a target picture is preceded by a subliminally presented visual contour or an unobtrusively presented word that either matches or mismatches the target picture. In other studies, fluency is manipulated by subtle variations of the presentation duration, clarity, figureground contrast, prototypicality, or symmetry of the target stimulus. Independent of the specific stimuli and manipulations used, the results of all studies converge on a simple conclusion: Participants like the easy-to-process stimuli more.

Psychophysiological contributions. To further understand the processes underlying the influence of processing fluency on liking, we drew on psychophysiological methods. Some researchers argue that the effect of repetition on liking, as well as the effect of other stimulus manipulations such as priming or duration, can be fully explained by cognitive mechanisms. According to such a "cold" account, these effects occur because participants (mis)attribute the enhanced fluency to liking, just as participants (mis)attribute fluency to fame, loudness, clarity, or previous occurrence (Bornstein \& D’Agostino, 1994; Klinger \& Greenwald, 1994; for a related account based on the notion of "nonspecific" activation, see Mandler, Nakamura, \& Van Zandt, 1987). In short, according to these accounts, liking for the mere-exposed stimulus is not genuine but an artifact of the judgment task. However, an alternative "hot" affective account of fluency proposes that changes in processing dynamics elicit a genuine affective response. This response may arise because fluency indicates that an external stimulus is familiar and therefore unlikely to be harmful (Zajonc, 1998), or because fluency reflects a low level of representational conflict (Bush, Luu, \& Posner, 2000; Derryberry \& Tucker, 1994; Fernadez-Duque, Baird, \& Posner, 2000), or because fluency indicates progress toward successful stimulus interpretation (Carver \& Scheier, 1990; Ramachandran \& Hirstein, 1999; Vallacher \& Nowak, 1999).

As discussed earlier, traditional methods such as self-reports and reaction times are very limited in their ability to distinguish between cognitive and affective accounts. Therefore, we used facial EMG techniques to test whether increasing perceptual fluency leads not only to increases in liking judgment, but also to increases in activity over the cheek muscle region-an indicator of positive affect. A series of studies using various fluency manipulations found that easy-to-process stimuli generated stronger responses over the cheek region than did hard-to-process stimuli, consistent with the posited increase in positive affect (Winkielman \& Cacioppo, 2001). These findings are consistent with demonstrations that mereexposed (i.e., highly fluent) stimuli generate stronger EMG responses over the cheek region than do novel stimuli (Harmon-Jones \& Allen, 2001).

Fluency and the mere-exposure effect. As noted earlier, research into the fluency-liking link was initially stimulated by research into the mere-exposure effect (Zajonc, 1968). The studies we just reviewed are consistent with the idea that repetition may be only one manipulation that enhances fluency. However, our studies also make clear that this enhancement of fluency is hedonically positive. 
There is now accumulating evidence that mere exposure elicits genuine positive affect in a more immediate way than envisioned by most cognitive interpretations. For example, in one study, participants were subliminally exposed to 25 pictures of Chinese ideographs and were later asked to report their current mood. For some participants, each of the 25 ideographs was different; for other participants, 5 different ideographs were repeated five times each (Monahan, Murphy, \& Zajonc, 2000). The results showed that participants who were subliminally exposed to repeated ideographs later reported being in a better mood than participants exposed to 25 different ideographs. In combination, the study by Monahan et al. (2000) and the just-discussed EMG study by Harmon-Jones and Allen (2001) demonstrate that stimulus repetition can elicit genuine positive affective responses, as has been observed for other manipulations of processing fluency.

Preferences without inferences. How do such effects relate to the question of rationality of preferences? We suggest that fluency-based liking can be considered "subrational" because it emerges from processes that have little to do with stimulus meaning. A fluent stimulus (picture, word, sentence, or argument) can carry the same meaning as a disfluent stimulus, yet it can elicit a more favorable affective reaction. The underlying process that makes this possible derives from the organism's ability to monitor not only the content of the representations being processed, but also a nonspecific signal about the quality of internal processing. Indeed, recent work in cognitive neuroscience suggests that a fluency signal may reflect rudimentary parameters of the dynamics of a neural response and, under some conditions, can be accessed at very early processing stages, independently of the explicit representation of the stimulus content (e.g., Aggleton \& Brown, 1999; Curran, 2000; Rugg et al., 1998). Assuming that the affect system indeed draws on this early signal, this mechanism explains how we can like a fluent stimulus even before we know what it is (Winkielman, Schwarz, \& Nowak, 2002).

Processing ease and political behavior. Manipulations that facilitate processing, and thus influence liking, abound in politics. The best known of such manipulations is, of course, repetition. Billboards, media advertisements, bumper stickers, and catchy slogans seem to form a cornerstone of any campaign. Are such techniques effective? On 17 July 1969, the New York Times reported that voters in a small town in Ecuador elected a foot powder named "Pulvapies" as their mayor in a write-in ballot. Before the election, "Pulvapies" had been extensively advertised on billboards around town with the slogan "Vote for any candidate, but if you want well-being and hygiene, vote for Pulvapies." More systematic observations concur. For example, Miller (1976) found that moderate amounts of repetition increased people's positive attitudes toward policy slogans such as "reduce foreign aid."

As discussed above, our research shows that repetition is just one of the many ways to facilitate processing and thus elicit a positive affective response. If so, our framework may explain the emphasis on sound bites, memorable slogans, 
catchy logos, and polished communication style in modern political campaigns. All of these manipulations enhance the ease with which the political message can be processed (perceived, encoded, interpreted, memorized, expressed), making it perceptually and conceptually "easy to swallow." As a result, voters may experience a positive affective reaction, and, not being aware of the true source of this reaction, they may misattribute it to the message, enhancing its evaluation for reasons that have nothing to do with the actual content (Schwarz \& Clore, 1983). Some demonstrations of this process exist in the consumer domain (Janiszewski \& Meyvis, 2001; Shapiro, 1999). Future studies may explicitly test the role of fluency-based affective reactions in the domain of political attitudes.

\section{Conclusions}

The evidence discussed above suggests that people's liking and wanting reactions reflect not only higher-level, belief-based influences, but also "core" affective and motivational processes. There appears to be a "wanting" dopamine system that influences the pursuit of rewards independently of cognitive expectations about them. In extreme cases, excessive "wanting" may produce strongly irrational choices, causing individuals to "want" what they do not cognitively want, and to choose what they do not expect to like. In a similar way, people can be induced by subliminal stimuli such as emotional facial expressions to have unconscious liking reactions, which can influence their subsequent evaluations of events. Liking reactions can also reflect such rudimentary processes as changes in the ease with which information can be processed. As a result, people can have subrational preferences that have little to do with conscious cognitive beliefs and are resistant to rational persuasion.

Contemporary understanding of rudimentary processes of liking and wanting has greatly benefited from the dialogue between psychology and neuroscience. This new understanding may carry implications that extend to political psychology as well. As discussed, neuroscientific theory and data on the liking and wanting system have led researchers to move beyond expectancy-value and drive theories in explaining motivation and choice. Psychophysiological methods also helped researchers discriminate between affective and cognitive accounts of responses to emotional facial expressions and the influence of fluency on liking. Hence, this paper exemplifies the benefits of collaboration between social scientists and cognitive, affective, and motivational neuroscientists. Such collaboration can prove invaluable in refining our theories and in testing alternative accounts of our phenomena. Even more important, such collaboration can help us bridge levels of explanations and lead to a more comprehensive account of the social mind (Cacioppo \& Berntson, 1992; Winkielman, Berntson, \& Cacioppo, 2001). As we have emphasized, we can currently offer only speculations on how the rudimentary affective and motivational processes addressed in our research play out in the political arena. However, we hope this review will inspire political 
psychologists to consider exploring the implications of these processes in their domain.

\section{ACKNOWLEDGMENTS}

We thank Penny Visser and John Cacioppo for their guidance and the reviewers for remarkably helpful suggestions. We also thank Tedra Fazendeiro, Kent Harber, Bruce Morton, Jeanne Shinskey, Valerie Stone, and Julie Wilbarger for their help at various stages of this manuscript. Correspondence concerning this article should be sent to Piotr Winkielman, Department of Psychology, University of California, San Diego, 9500 Gillman Drive, La Jolla, CA 92093 (E-mail: pwinkiel@ucsd.edu) or to Kent Berridge, Department of Psychology, University of Michigan, Ann Arbor, MI 48106 (E-mail: berridge@umich.edu).

\section{REFERENCES}

Abelson, R. P., Kinder, D. R., Peters, M. D., \& Fiske, S. T. (1982). Affective and semantic components in political person perception. Journal of Personality and Social Psychology, 42, 619-630.

Aggleton, J. P., \& Brown, M. W. (1999). Episodic memory, amnesia and the hippocampal-anterior thalamic axis. Behavioral and Brain Sciences, 22, 425-498.

Aharon, I., Etcoff, N., Ariely, D., Chabris, C. F., O'Connor, E., \& Breiter, H. C. (2001). Beautiful faces have variable reward value: fMRI and behavioral evidence. Neuron, 32, 537-551.

Anderson, A. K., \& Phelps, E. A. (2001). The human amygdala supports affective modulatory influences on visual awareness. Nature, 411, 305-309.

Anderson, A. K., \& Phelps, E. A. (2002). Is the human amygdala critical for the subjective experience of emotion? Evidence of intact dispositional affect in patients with amygdala lesions. Journal of Cognitive Neuroscience, 14, 709-720.

Balleine, B. W., \& Dickinson, A. (1998). Goal-directed instrumental action: Contingency and incentive learning and their cortical substrates. Neuropharmacology, 37, 407-419.

Bechara, A., Damasio, H., \& Damasio, A. R. (2000). Emotion, decision making, and the orbitofrontal cortex. Cerebral Cortex, 10, 295-307.

Bechara, A., Dolan, S., \& Hindes, A. (2002). Decision-making and addiction (part II): Myopia for the future or hypersensitivity to reward? Neuropsychologia, 40, 1690-1705.

Berke, R. L. (2000, 12 September). Democrats see, and smell, rats in G.O.P. ad. New York Times, p. 1.

Berridge, K. C. (1999). Pleasure, pain, desire, and dread: Hidden core processes of emotion. In D. Kahneman, E. Diener, \& N. Schwarz (Eds.), Well-being: The foundations of hedonic psychology (pp. 525-557). New York: Russell Sage Foundation.

Berridge, K. C. (2001). Reward learning: Reinforcement, incentives, and expectations. Psychology of Learning and Motivation, 40, 223-278.

Berridge, K. C. (2003). Irrational pursuit: Hyper-incentives from a visceral brain. In I. Brocas \& J. D. Carrillo (Eds.), Economics and psychology (pp. 17-40). Oxford: Oxford University Press.

Berridge, K. C., \& Robinson, T. E. (1998). What is the role of dopamine in reward: Hedonic impact, reward learning, or incentive salience? Brain Research Reviews, 28, 309-369.

Berridge, K. C., \& Winkielman, P. (2003). What is an unconscious emotion? The case for unconscious "liking." Cognition and Emotion, 17, 181-211. 
Bindra, D. (1978). How adaptive behavior is produced: A perceptual-motivational alternative to response-reinforcement. Behavioral and Brain Sciences, 1, 41-91.

Bornstein, R. F. (1989). Exposure and affect: Overview and meta-analysis of research, 1968-1987. Psychological Bulletin, 106, 265-289.

Bornstein, R. F., \& D'Agostino, P. R. (1994). The attribution and discounting of perceptual fluency: Preliminary tests of a perceptual fluency/attributional model of the mere exposure effect. Social Cognition, 12, 103-128.

Bradley, M. M. (2000). Emotion and motivation. In J. T. Cacioppo, L. G. Tassinary, \& G. G. Berntson (Eds.), Handbook of psychophysiology (pp. 602-642). New York: Cambridge University Press.

Bush, G., Luu, P., \& Posner, M. I. (2000). Cognitive and emotional influences in anterior cingulate cortex. Trends in Cognitive Sciences, 4, 215-222.

Cabanac, M. (1971). Physiological role of pleasure. Science, 173, 1103-1107.

Cacioppo, J. T., \& Berntson, G. G. (1992). Social psychological contributions to the decade of the brain: Doctrine of multilevel analysis. American Psychologist, 47, 1019-1028.

Carver, C. S., \& Scheier, M. F. (1990). Origins and functions of positive and negative affect: A controlprocess view. Psychological Review, 97, 19-35.

Clore, G. L., \& Colcombe, S. (2003). The parallel worlds of affective concepts and feelings. In J. Musch \& K. C. Klauer (Eds.), The psychology of evaluation: Affective processes in cognition and emotion (pp. 335-369). Mahwah, NJ: Erlbaum.

Conover, P. J., \& Feldman, S. (1986). Emotional reactions to the economy: I'm mad as hell and I'm not going to take it anymore. American Journal of Political Science, 30, 50-78.

Cosmides, L., \& Tooby, J. (2000). Evolutionary psychology and the emotions. In M. Lewis \& J. M. Haviland-Jones (Eds.), The handbook of emotions (pp. 91-115). New York: Oxford University Press.

Critchley, H., Daly, E., Phillips, M., Brammer, M., Bullmore, E., Williams, S., Van Amelsvoort, T., Robertson, D., David, A., \& Murphy, D. (2000). Explicit and implicit neural mechanisms for processing of social information from facial expressions: A functional magnetic resonance imaging study. Human Brain Mapping, 9, 93-105.

Curran, T. (2000). Brain potentials of recollection and familiarity. Memory and Cognition, 28, 923-938.

Damasio, A. R. (1999). The feeling of what happens: Body and emotion in the making of consciousness. New York: Harcourt Brace.

Damasio, A. R., Grabowski, T. J., Bechara, A., Damasio, H., Ponto, L. L. B., Parvizi, J., \& Hichwa, R. D. (2000). Subcortical and cortical brain activity during the feeling of self-generated emotions. Nature Neuroscience, 3, 1049-1056.

Derryberry, D., \& Tucker, D. M. (1994). Motivating the focus of attention. In P. M. Niedenthal \& S. Kitayama (Eds.), The heart's eye: Emotional influences in perception and attention (pp. 167-196). San Diego, CA: Academic Press.

Desimone, R., Miller, E. K., Chelazzi, L., \& Lueschow, A. (1995). Multiple memory systems in the visual cortex. In M. S. Gazzaniga (Ed.), The cognitive neurosciences (pp. 475-490). Cambridge, MA: MIT Press.

de Sousa, R. (1987). The rationality of emotions. Cambridge, MA: MIT Press.

Dickinson, A. J., \& Balleine, B. (2002). The role of learning in the operation of motivational systems. In C. R. Gallistel (Ed.), Steven's handbook of experimental psychology. Vol. 3: Learning, motivation, and emotion (pp. 497-534). New York: Wiley.

Dickinson, A., Smith, J., \& Mirenowicz, J. (2000). Dissociation of Pavlovian and instrumental incentive learning under dopamine antagonists. Behavioral Neuroscience, 114, 468-483.

Dijksterhuis, A., \& Bargh, J. A. (2001). The perception-behavior expressway: Automatic effects of social perception on social behavior. Advances in Experimental Social Psychology, 33, 1-40.

Dimberg, U., \& Öhman, A. (1996). Behold the wrath: Psychophysiological responses to facial stimuli. Motivation and Emotion, 20, 149-182. 
Dimberg, U., Thunberg, M., \& Elmehed, K. (2000). Unconscious facial reactions to emotional facial expressions. Psychological Science, 11, 86-89.

Edwards, K. (1990). The interplay of affect and cognition in attitude formation and change. Journal of Personality and Social Psychology, 59, 202-216.

Ekman, P. (1984). Expression and the nature of emotion. In K. Scherer \& P. Ekman (Eds.), Approaches to emotion (pp. 319-343). Hillsdale, NJ: Erlbaum.

Ellsworth, P. C., \& Scherer, K. (2003). Appraisal processes in emotion. In R. J. Davidson, H. Goldsmith, \& K. R. Scherer (Eds.), Handbook of the affective sciences (pp. 572-595). New York: Oxford University Press.

Elster, J. (1999). Strong feelings: Emotion, addiction, and human behavior. Cambridge, MA: MIT Press.

Fabrigar, L. R., \& Petty, R. E. (1999). The role of the affective and cognitive basis of attitudes in susceptibility to affectively and cognitively based persuasion. Personality and Social Psychology Bulletin, 25, 363-381.

Fernandez-Duque, D., Baird, J. A., \& Posner, M. I. (2000). Executive attention and metacognitive regulation. Consciousness and Cognition, 9, 288-307.

Frijda, N. H. (1999). Emotions and hedonic experience. In D. Kahneman, E. Diener, \& N. Schwarz (Eds.), Well-being: The foundations of hedonic psychology (pp. 190-210). New York: Russell Sage Foundation.

Gilbert, D. T., \& Wilson, T. D. (2000). Miswanting: Some problems in forecasting future affective states. In J. P. Forgas (Ed.), Feeling and thinking: The role of affect in social cognition (pp. 178-197). Cambridge: Cambridge University Press.

Glaser, J., \& Salovey, P. (1998). Affect in electoral politics. Personality and Social Psychology Review, 2, 156-172.

Greenwald, A. G. (1992). New Look 3: Unconscious cognition reclaimed. American Psychologist, 47, 766-779.

Haber, R. N., \& Hershenson, M. (1965). The effects of repeated brief exposures on growth of a percept. Journal of Experimental Psychology, 69, 40-46.

Harmon-Jones, E., \& Allen, J. J. B. (2001). The role of affect in the mere exposure effect: Evidence from psychophysiological and individual differences approaches. Personality and Social Psychology Bulletin, 27, 889-898.

Heilbroner, R. L., \& Malone, L. J. (1986). The essential Adam Smith. New York: Norton.

Higgins, E. T. (1996). Knowledge activation: Accessibility, applicability, and salience. In E. T. Higgins \& A. W. Kruglanski (Eds.), Social psychology: Handbook of basic principles (pp. 133-168). New York: Guilford.

Higgins, E. T., \& Kruglanski, A. W. (Eds.) (2000). Motivational science. Philadelphia: Psychology Press.

Holbrook, A. L., Krosnick, J. A., Visser, P. S., Gardner, W., \& Cacioppo, J. T. (2001). Attitudes toward presidential candidates and political parties: Initial optimism, inertial first impressions, and a focus on the flaws. American Journal of Political Science, 45, 930-950.

Hull, C. L. (1951). Essentials of behavior. New Haven, CT: Yale University Press.

Jacoby, L. L., \& Dallas, M. (1981). On the relationship between autobiographical memory and perceptual learning. Journal of Experimental Psychology: General, 110, 306-340.

Janiszewski, C., \& Meyvis, T. (2001). Effects of brand logo complexity, repetition, and spacing on processing fluency and judgment. Journal of Consumer Research, 28, 18-32.

Kahneman, D. (1999). Objective happiness. In D. Kahneman, E. Diener, \& N. Schwarz (Eds.), Wellbeing: The foundations of hedonic psychology (pp. 3-25). New York: Russell Sage Foundation.

Kahneman, D., Wakker, P. P., \& Sarin, R. (1997). Back to Bentham? Explorations of experienced utility. Quarterly Journal of Economics, 112, 375-405. 
Kampe, K. K. W., Frith, C. D., Dolan, R. J., \& Frith, U. (2001). Reward value of attractiveness and gaze. Nature, 413, 589-590.

Kihlstrom, J. F., Mulvaney, S., Tobias, B. A., \& Tobis, I. P. (2000). The emotional unconscious. In E. Eich, J. F. Kihlstrom, G. H. Bower, J. P. Forgas, \& P. M. Niedenthal (Eds.), Cognition and emotion (pp. 30-86). New York: Oxford University Press.

Klinger, M. R., \& Greenwald, A. G. (1994). Preferences need no inferences?: The cognitive basis of unconscious mere exposure effects. In P. M. Niedenthal \& S. Kitayama (Eds.), The heart's eye: Emotional influences in perception and attention (pp. 67-85). San Diego, CA: Academic Press.

Knutson, B., Adams, C. M., Fong, G. W., \& Hommer, D. (2001). Anticipation of increasing monetary reward selectively recruits nucleus accumbens. Journal of Neuroscience, 21, 1-5.

Kuklinski, J. H., Riggle, E., Ottati, V., Schwarz, N., \& Wyer, R. S. (1991). The cognitive and affective bases of political tolerance judgments. American Journal of Political Science, 35, 1-27.

LaFrance, M., \& Hecht, M. A. (1995). Why smiles generate leniency. Personality and Social Psychology Bulletin, 21, 207-214.

Lane, R., Kaszniak, A., Ahern, G., \& Schwartz, G. (1997). Is alexithymia the emotional equivalent of blindsight? Biological Psychiatry, 42, 834-844.

Lang, P. J. (1993). The three-system approach to emotion. In N. Birbaumer \& A. Öhman (Eds.), The structure of emotion: Psychophysiological, cognitive, and clinical aspects (pp. 18-30). Seattle: Hogrefe \& Huber.

Lavine, H., Borgida, E., \& Sullivan, J. L. (2000). On the relationship between attitude involvement and attitude accessibility: Toward a cognitive-motivational model of political information processing. Political Psychology, 21, 81-106.

Lazarus, R. S. (1999). The cognition-emotion debate: A bit of history. In T. Dalgleish \& M. Power (Eds.), Handbook of cognition and emotion (pp. 3-19). Chichester, UK: Wiley.

LeDoux, J. (1996). The emotional brain: The mysterious underpinnings of emotional life. New York: Simon \& Schuster.

Losier, G. F., \& Koestner, R. (1999). Intrinsic versus identified regulation in distinct political campaigns: The consequences of following politics for pleasure versus personal meaningfulness. Personality and Social Psychology Bulletin, 25, 287-298.

Mandler, G., Nakamura, Y., \& Van Zandt, B. J. (1987). Nonspecific effects of exposure on stimuli that cannot be recognized. Journal of Experimental Psychology: Learning, Memory, and Cognition, $13,646-648$.

Marcus, G. E., \& MacKuen, M. B. (1993). Anxiety, enthusiasm, and the vote: The emotional underpinnings of learning and involvement during presidential campaigns. American Political Science Review, 87, 672-685.

McHugo, G. J., Lanzetta, J. T., Sullivan, D. G., Masters, R. D., \& Englis, B. G. (1985). Emotional reactions to a political leader's expressive displays. Journal of Personality and Social Psychology, 49, 1513-1529.

Mellers, B. A. (2000). Choice and the relative pleasure of consequences. Psychological Bulletin, 126, 910-924.

Miller, R. L. (1976). Mere exposure, psychological reactance and attitude change. Public Opinion Quarterly, 40, 229-233.

Monahan, J. L., Murphy, S. T., \& Zajonc, R. B. (2000). Subliminal mere exposure: Specific, general, and diffuse effects. Psychological Science, 6, 462-466.

Morris, J. S., DeGelder, B., Weiskrantz, L., \& Dolan, R. J. (2001). Differential extrageniculostriate and amygdala responses to presentation of emotional faces in a cortically blind field. Brain, 124, $1241-1252$.

Morris, J. S., Öhman, A., \& Dolan, R. J. (1998). Conscious and unconscious emotional learning in the human amygdala. Nature, 393, 467-470. 
Morris, J. S., Öhman, A., \& Dolan, R. J. (1999). A subcortical pathway to the right amygdala mediating "unseen" fear. Proceedings of the National Academy of Sciences, U.S.A., 96, 1680-1685.

Mowrer, O. H. (1960). Learning theory and behavior. New York: Wiley.

Mullen, B., Futrell, D., Stairs, D., Tice, D. M., Baumeister, R. F., Dawson, K. E., Roirdan, C. A., Radloff, C. E., Goethals, G. R., Kennedy, J. G., \& Rosenfeld, P. (1986). Newscasters' facial expressions and voting behavior of viewers: Can a smile elect a president? Journal of Personality and Social Psychology, 51, 291-295.

Murphy, S. T., Monahan, J. L., \& Zajonc, R. B. (1995). Additivity of nonconscious affect: Combined effects of priming and exposure. Journal of Personality and Social Psychology, 69, 589602.

Murphy, S. T., \& Zajonc, R. B. (1993). Affect, cognition, and awareness: Affective priming with optimal and suboptimal stimulus exposures. Journal of Personality and Social Psychology, 64, 723-739.

Nesse, R. M. (1990). Evolutionary explanations of emotions. Human Nature, 1, 261-289.

Niedenthal, P. M. (1990). Implicit perception of affective information. Journal of Experimental Social Psychology, 26, 505-527.

Petty, R. E., \& Cacioppo, J. T. (1986). Communication and persuasion: Central and peripheral routes to attitude change. New York: Springer-Verlag.

Pittman, T. S. (1998). Motivation. In D. T. Gilbert, S. T. Fiske, \& G. Lindzey (Eds.), The handbook of social psychology (vol. 1, 4th ed., pp. 549-590). Boston: McGraw-Hill.

Ramachandran, V. S., \& Hirstein, W. (1999). The science of art: A neurological theory of aesthetic experience. Journal of Consciousness Studies, 6, 15-51.

Reber, R., Winkielman, P., \& Schwarz, N. (1998). Effects of perceptual fluency on affective judgments. Psychological Science, 9, 45-48.

Rilling, J. K., Gutman, D. A., Zeh, T. R., Pagnoni, G., Berns, G. S., \& Kilts, C. D. (2002). A neural basis for social cooperation. Neuron, 35, 395-405.

Robinson, T. E., \& Berridge, K. C. (1993). The neural basis of drug craving: An incentivesensitization theory of addiction. Brain Research Reviews, 18, 247-291.

Robinson, T. E., \& Berridge, K. C. (2000). The psychology and neurobiology of addiction: An incentive-sensitization view. Addiction, 95, 91-117.

Robinson, T. E., Browman, K. E., Crombag, H. S., \& Badiani, A. (1998). Modulation of the induction or expression of psychostimulant sensitization by the circumstances surrounding drug administration. Neuroscience and Biobehavioral Reviews, 22, 347-354.

Rolls, E. T., Baylis, G. C., Hasselmo, M. E., \& Nalwa, V. (1989). The effect of learning on the face selective responses of neurons in the cortex in the superior temporal sulcus of the monkey. Experimental Brain Research, 76, 153-164.

Rotteveel, M., de Groot, P., Geutskens, A., \& Phaf, R. H. (2001). Stronger suboptimal than optimal affective priming? Emotion, 1, 348-364.

Rugg, M. D., Mark, R. E., Walla, P., Schloerscheidt, A. M., Birch, C. S., \& Allan, K. (1998). Dissociation of the neural correlates of implicit and explicit memory. Nature, 392, 595-598.

Schwarz, N., \& Clore, G. L. (1983). Mood, misattribution, and judgments of well-being: Informative and directive functions of affective states. Journal of Personality and Social Psychology, 45, 513-523.

Schwarz, N., \& Clore, G. L. (1996). Feelings and phenomenal experiences. In E. T. Higgins \& A. W. Kruglanski (Eds.), Social psychology: Handbook of basic principles (pp. 433-465). New York: Guilford.

Seamon, J. G., Brody, N., \& Kauff, D. (1983). Affective discrimination of stimuli that are not recognized: Effects of shadowing, masking, and cerebral laterality. Journal of Experimental Psychology: Learning, Memory, and Cognition, 9, 544-555. 
Shapiro, S. (1999). When an ad's influence is beyond our conscious control: Perceptual and conceptual fluency effects caused by incidental ad exposure. Journal of Consumer Research, 26, 16-36.

Spinoza, B. (1883). The ethics (R. H. M. Elwes, Trans.). London: George Bell and Sons.

Steiner, J. E., Glaser, D., Hawilo, M. E., \& Berridge, K. C. (2001). Comparative expression of hedonic impact: Affective reactions to taste by human infants and other primates. Neuroscience and Biobehavioral Reviews, 25, 53-74.

Strahan, E. J., Spencer, S. J., \& Zanna, M. P. (2003). Subliminal priming and persuasion: Striking while the iron is hot. Journal of Experimental Social Psychology, 38, 556-568.

Tatarkiewicz, W. (1970). History of aesthetics. The Hague: Mouton.

Toates, F. (1986). Motivational systems. Cambridge: Cambridge University Press.

Tomkins, S. S. (1962). Affect, imagery, consciousness. New York: Springer.

Vallacher, R. R., \& Nowak, A. (1999). The dynamics of self-regulation. In R. S. Wyer Jr. (Ed.), Perspectives on behavioral self-regulation (pp. 241-259). Mahwah, NJ: Erlbaum.

Washton, A. M., \& Stone-Washton, N. (1993). Outpatient treatment of cocaine and crack addiction: A clinical perspective. In F. M. Tims \& C. G. Leukefeld (Eds.), Cocaine treatment: Research and clinical perspectives (NIDA Research Monograph 135, pp. 15-30). Rockville, MD: National Institute on Drug Abuse.

Weiner, B. (1985). An attributional theory of achievement motivation and emotion. Psychological Review, 92, 548-573.

Whalen, P., Rauch, S. L., Etcoff, N. L., McInerney, S. C., Lee, M. B., \& Jenike, M. A. (1998). Masked presentations of emotional facial expressions modulate amygdala activity without explicit knowledge. Journal of Neuroscience, 18, 411-418.

Whittlesea, B. W. A., Jacoby, L. L., \& Girard, K. (1990). Illusions of immediate memory: Evidence of an attributional basis for feelings of familiarity and perceptual quality. Journal of Memory and Language, 29, 716-732.

Wilson, T. D., \& Brekke, N. (1994). Mental contamination and mental correction: Unwanted influences on judgments and evaluations. Psychological Bulletin, 116, 117-142.

Wilson, T. D., Lindsey, S., \& Schooler, T. Y. (2000). A model of dual attitudes. Psychological Review, $107,101-126$.

Winkielman, P., Berntson, G. G., \& Cacioppo, J. T. (2001). The psychophysiological perspective on the social mind. In A. Tesser \& N. Schwarz (Eds.), Blackwell handbook of social psychology: Intraindividual processes (pp. 89-108). Oxford: Blackwell.

Winkielman, P., \& Berridge, K. C. (in press). Unconscious emotion. Current Directions in Psychological Science.

Winkielman, P., Berridge, K. C., \& Wilbarger, J. (2002). Subliminal affective priming of hedonic value: Unconscious affective reactions to masked happy versus angry faces influence consumption behavior and drink evaluations. Manuscript submitted for publication.

Winkielman, P., \& Cacioppo, J. T. (2001). Mind at ease puts a smile on the face: Psychophysiological evidence that processing facilitation increases positive affect. Journal of Personality and Social Psychology, 81, 989-1000.

Winkielman, P., Schwarz, N., Fazendeiro, T., \& Reber, R. (2003). The hedonic marking of processing fluency: Implications for evaluative judgment. In J. Musch \& K. C. Klauer (Eds.), The psychology of evaluation: Affective processes in cognition and emotion (pp. 189-217). Mahwah, NJ: Erlbaum.

Winkielman, P., Schwarz, N., \& Nowak, A. (2002). Affect and processing dynamics: Perceptual fluency enhances evaluations. In S. Moore \& M. Oaksford (Eds.), Emotional cognition: From brain to behaviour (pp. 111-136). Amsterdam: John Benjamins.

Winkielman, P., Zajonc, R. B., \& Schwarz, N. (1997). Subliminal affective priming resists attributional interventions. Cognition and Emotion, 11, 433-465. 
Winter, D. G. (1993). Power, affiliation, and war: Three tests of a motivational model. Journal of Personality and Social Psychology, 65, 532-545.

Witherspoon, D., \& Allan, L. G. (1985). The effects of a prior presentation on temporal judgments in a perceptual identification task. Memory and Cognition, 13, 103-111.

Wyvell, C. L., \& Berridge, K. C. (2000). Intra-accumbens amphetamine increases the conditioned incentive salience of sucrose reward: Enhancement of reward "wanting" without enhanced "liking" or response reinforcement. Journal of Neuroscience, 20, 8122-8130.

Wyvell, C. L., \& Berridge, K. C. (2001). Incentive sensitization by previous amphetamine exposure: Increased cue-triggered "wanting" for sucrose reward. Journal of Neuroscience, 21, 7831-7840.

Zajonc, R. B. (1968). Attitudinal effects of mere exposure. Journal of Personality and Social Psychology: Monograph Supplement, 9, 1-27.

Zajonc, R. B. (1980). Feeling and thinking: Preferences need no inferences. American Psychologist, 35, 117-123.

Zajonc, R. B. (1998). Emotions. In D. T. Gilbert, S. T. Fiske, \& G. Lindzey (Eds.), The handbook of social psychology (vol. 1, 4th ed., pp. 591-632). Boston: McGraw-Hill.

Zajonc, R. B. (2000). Feeling and thinking: Closing the debate over the independence of affect. In J. P. Forgas (Ed.), Feeling and thinking: The role of affect in social cognition (pp. 31-58). Cambridge: Cambridge University Press. 